\title{
Senescence of human vocal fold fibroblasts in primary culture
}

\author{
George M. Adams ${ }^{1}$, Chet C. Xu ${ }^{1}$, Roger W. Chan ${ }^{1,2}$ \\ ${ }^{1}$ Otolaryngology, Head and Neck Surgery, University of Texas Southwestern Medical Center, Dallas, USA; \\ ${ }^{2}$ Biomedical Engineering, University of Texas Southwestern Medical Center, Dallas, USA. \\ Email: roger.chan@utsouthwestern.edu
}

Received 1 October 2009; revised 18 December 2009; accepted 21 December 2009.

\begin{abstract}
This study examined the replicative senescence of primary-culture human vocal fold fibroblasts, in terms of changes in gross chromosomal structure with subculturing, and population doubling time (PDT). The mRNA expressions of $\mathbf{1 4}$ target genes were also examined. The objectives were to identify the onset of senescence for establishing the acceptable limit of sub-culturing, and to better understand the effect of cellular aging on matrix protein regulation in the vocal fold. Gross chromosomal changes in vocal fold fibroblasts from a 58-year-old woman were karyotyped with Giemsa stain. Proliferation of the fibroblasts was determined with cell recovery and PDT calculation. Transcript levels of the target genes were found by RT-PCR. Onset of significant chromosomal anomalies was seen with passage 5. For mRNA expressions, significant increases with passaging were observed in collagenase, macrophage elastase, lysyl oxidase and fibromodulin, whereas significant downregulation was detected in decorin, procollagen $I$, hyaluronic acid-synthase 2 and collagen III. This modulation pattern suggested that fibroblasts underwent in vitro aging, consistent with the significant increase in PDT. The inception of senescence did not occur until passage 5. These findings may facilitate the development of representative in vitro models for testing tissue engineering approaches involving primary-culture fibroblasts.
\end{abstract}

Keywords: Larynx; Extracellular Matrix; Cell Proliferation; Replicative Senescence; Tissue Engineering

\section{INTRODUCTION}

A better understanding of the biology of vocal fold fibroblasts is fundamental for establishing representative and consistent in vitro models of the vocal fold lamina propria extracellular matrix (ECM), where fibroblasts are the predominant cell type [1,2]. Such in vitro models are critical for the development of tissue engineering approaches for the treatment of a variety of vocal pa- thologies. Tissue engineering, or regenerative medicine approaches involve the fabrication of tissue substitutes that can be used to surgically augment, replace, and functionally repair tissue defects in the lamina propria, e.g., vocal fold scarring, atrophy, sulculs vocalis, and tissue deficiencies left with the surgical removal of tumors [3]. Vocal fold fibroblasts are responsible for the homeostatic expressions of key ECM components of the lamina propria, including fibrous proteins (e.g., collagen, elastin), proteoglycans (e.g., decorin, fibromodulin, versican, biglycan), glycosaminoglycans (e.g., hyaluronic acid), and structural glycoproteins (e.g., fibronectin) $[1,2]$. Expressions of these ECM proteins contribute to the optimal tissue viscoelastic properties crucial for functional voice production, since the lamina propria is the primary tissue layer responsible for flow-induced selfoscillation of the vocal fold [4]. The structural and functional integrity of the ECM depends on the proliferation, metabolic activities, and turnover rate of vocal fold fibroblasts. ECM changes have often been studied with cultured vocal fold fibroblasts, yet it is well established that fibroblasts in vitro are influenced by a phenomenon known as replicative senescence, an in vitro form of aging somewhat parallel to the senescent processes in vivo [5]. Cells undergo replicative senescence after repeated subculturing for a number of passages. Replicative senescence is characterized by decreased cellular proliferation, resistance to mitosis, and avoidance of programmed cell death or apoptosis $[5,6]$.

Thibeault et al. examined the karyotypes of normal vocal fold fibroblasts and tracheal scar fibroblasts from primary culture, across different passages (passages 3, 4, 5,6 and 10) [7]. Normal vocal fold fibroblasts displayed multiple chromosomal abnormalities including loss of the $\mathrm{Y}$ chromosome, translocations, multiple rearrangements, and tetraploidy of all chromosomes excluding the Y chromosome. With tracheal scar fibroblasts, no aberrations were detected in the early passages while 15 of 20 cells analyzed in the late passage showed tetraploidy in all but the sex chromosome. While these data provided an initial understanding of chromosomal abnormalities in primary vocal fold fibroblasts, the onset of 
these abnormalities with passaging was not known, particularly in early passages (before passage 3 ). This study attempted to determine the inception of these anomalies using detailed cytogenetic analyses of early and late passages (passages 1-5, and passage 10) of normal primary-culture human vocal fold fibroblasts. The expressions of key matrix proteins in the lamina propria ECM and their protein precursors, as well as those of the matrix-synthesizing and matrix-degrading enzymes at the mRNA level were examined by reverse transcriptasepolymerase chain reaction (RT-PCR). The rate of proliferation of the fibroblasts was also investigated by measurement of the population doubling time (PDT). Our goals were: 1) to identify the onset of senescent mechanisms for establishing an acceptable limit of sub-culturing; and 2) to better understand the effect of cellular aging on the homeostatic regulation of matrix proteins in the vocal fold lamina propria, so that one could establish representative, consistent in vitro models of the ECM based on the acceptable limit of sub-culturing. Such models can serve as a platform for evaluating the impact of tissue engineering approaches on functional tissue remodeling and reconstruction, e.g., approaches based on the use of acellular bioscaffolds, polymeric substrates, or growth factors $[8,9,10]$.

\section{MATERIALS AND METHODS}

\subsection{Vocal Fold Tissue Culture}

Primary-culture vocal fold fibroblasts were obtained from the vocal ligament (intermediate and deep layers of the lamina propria) of a larynx excised from a 58-yearold Hispanic female who underwent total laryngectomy due to papillary columnar thyroid carcinoma. The laryngeal specimens were examined by an otolaryngologist as well as by a pathologist, and were certified to be free of cancerous tissue, i.e., without any epithelial to mesenchymal transition [11]. The protocols for the procurement of the laryngeal specimens and the subsequent experimental procedures were approved by the Institutional Review Board of UT Southwestern Medical Center. Using primary explant techniques as described in $\mathrm{Xu}$ et al. the specimens were disinfected with $70 \%$ ethanol, washed twice with phosphate-buffered saline (PBS), dissected using phonomicrosurgical instruments and cut into $1-$ to $2-\mathrm{mm}^{3}$ sections [8]. The tissue sections were then placed in a 24-well plate (one section per well) and supplemented with DMEM fortified with $20 \%$ fetal bovine serum (FBS) and $2 \%$ penicillin/streptomycin. Primary fibroblasts reproduced and migrated from the tissue sections over a two-week period prior to being subcultured, or passaged. The primary cells were authenticated as conventional vocal fold fibroblasts according to their morphological characteristics under light microscopy [12]. For sub-culturing, cells were grown to $60 \%$ confluence and treated with trypsin-EDTA for 3-4 $\mathrm{min}$ at $37^{\circ} \mathrm{C}$ with $5 \% \mathrm{CO}_{2}$. An equal volume of complete media was then added to the trypsinized suspension prior to centrifuging for $3 \mathrm{~min}$ at $1500 \mathrm{rpm}$. After removal of the supernatant, the pellet was resuspended in $8 \mathrm{ml}$ of complete media with $1 \mathrm{ml}$ added to a $75-\mathrm{cm}^{2}$ tissue culture flask (T-75), at 1:8 dilution. DMEM was then added $(20-25 \mathrm{ml})$ to the resuspension and cells were incubated at $37^{\circ} \mathrm{C}$ with $5 \% \mathrm{CO}_{2}$.

\subsection{Karyotype Analysis}

Karyotype analysis of primary-culture vocal fold fibroblasts of passages one through five (P1-P5) and ten (P10) and grown to $60 \%$ confluence was conducted at the Veripath Laboratories of UT Southwestern Medical Center (Dallas, TX). To induce cell cycle arrest and obtain sufficient numbers of cells in metaphase, colcemid (Roche Laboratories, Nutley, NJ) was added $(50 \mathrm{ng} / \mathrm{ml}$ final concentration) overnight for 12-16 hours prior to harvest. After trypsinization and centrifugation (1500 rpm for 5 min) along with subsequent aspiration of the supernatant, cells were treated with a hypotonic solution $(75 \mathrm{mM} \mathrm{KCl})$ for $25-30 \mathrm{~min}$ at $37^{\circ} \mathrm{C}$ to promote swelling and to allow for proper spreading and clear microscopic examination of the chromosomes.

Cells were fixed using a 3:1 mixture of methanol to glacial acetic acid (one ml volume) and mixed thoroughly prior to centrifugation (1500 rpm for $5 \mathrm{~min}$ ). After a second fixation step using a larger volume of fixative $(7 \mathrm{ml})$, cells were dropped onto microscope slides in an incubation chamber (Thermotron, Holland, MI) with constant humidity for proper spreading of the chromosomes. To allow for adsorption of chromosomes onto the glass surface, slides were incubated at $90^{\circ} \mathrm{C}$ for $30 \mathrm{~min}$ prior to G-banding by trypsin using Giemsa (GTG) stain.

For the G-banding procedure, heat-treated slides were immersed in trypsin (1:50 dilution with Isoton II buffer (Curtis Matheson Scientific, Houston, TX) for 1-2 min to remove extra chromosomal debris, then in Isoton II twice to remove trypsin. Two successive washes with $75 \%$ and $95 \%$ ethanol removed remnants of Isoton II and a subsequent wash in Gurr buffer eliminated any ethanol residue. Slides were stained (for 1-2 min) using Wright's solution (eosin methylene blue), rinsed with deionized water and dried with compressed air.

Images of G-banded chromosomes (or karyotypes) were acquired using the Case Data Manager Version 5.5.2.2 software (Applied Spectral Imaging, Vista, CA), which arranged chromosomes in a pairwise fashion. Karyotypes were generated for passages 1-5 and 10 using 20 metaphase cells. By using the standard number of 20 cells counted, mosaicism of greater than $14 \%$ frequency may be excluded at the $95 \%$ confidence level (i.e., $p<0.05$ ) [13]. To ensure the reliability and validity of the analysis, images were analyzed by four individuals certified in cytogenetic analysis and the karyotypes were documented. 
Table 1. Primer sequences and polymerase chain reaction parameters.

\begin{tabular}{|c|c|c|c|c|}
\hline Target & Primer Sequence & RNA (ng) & $\operatorname{AT}\left({ }^{\circ} \mathrm{C}\right)$ & $\mathrm{bp}$ \\
\hline GAPDH (control) & $\begin{array}{l}\text { F: GGTGTGAACCATGAGAAG } \\
\text { R: CTGTTGAAGTCAGAGGAGAC }\end{array}$ & 100 & 50 & 464 \\
\hline HA Receptor (CD44) & $\begin{array}{l}\text { F: GAAAGGAGCAGCACTTCAGG } \\
\text { R: CACTTGGCTTTCTGTCCTC }\end{array}$ & 100 & 50 & 397 \\
\hline Decorin & $\begin{array}{l}\text { F: GATGCAGCTAGCCTGAAAGG } \\
\text { R: TCACACCCGAATAAGAAGCC }\end{array}$ & 100 & 50 & 274 \\
\hline MMP-1 (Collagenase) & $\begin{array}{l}\text { F: CAACTTACATCGTGTTGCGG } \\
\text { R: ACCGGACTTCATCTCTGTCG }\end{array}$ & 100 & 50 & 395 \\
\hline GAPDH (control) & $\begin{array}{l}\text { F: ACCCAGAAGACTGTGGATGG } \\
\text { R: TGAGCTTGACAAAGTGGTCG }\end{array}$ & 100 & 56 & 382 \\
\hline Procollagen I & $\begin{array}{l}\text { F: GTTGGTGCTAAGGGTGAAGC } \\
\text { R: ACCGGACTTCATCTCTGTCG }\end{array}$ & 100 & 56 & 294 \\
\hline Fibronectin & $\begin{array}{l}\text { F: TACCAACCTACGGATGACTCG } \\
\text { R: CATCATCGTAACACGTTGCC }\end{array}$ & 100 & 56 & 300 \\
\hline GAPDH (control) & $\begin{array}{l}\text { F: AAGGTCGGAGTCAACGGATTTGGT } \\
\text { R: AGTGATGGCATGGACTGTGGTCAT }\end{array}$ & 100 & 60 & 534 \\
\hline HA-synthase 2 & $\begin{array}{l}\text { F: TACCAACCTACGGATGACTCG } \\
\text { R: CATCATCGTAACACGTTGCC }\end{array}$ & 100 & 60 & 403 \\
\hline Collagen I $(\alpha 2)$ & $\begin{array}{l}\text { F: TACCCTGGCAATATTGGTCCCGTT } \\
\text { R: GGCAGACCTTGCAATCCATTGTGT }\end{array}$ & 100 & 60 & 248 \\
\hline Collagen III $(\alpha 1)$ & $\begin{array}{l}\text { F: CTTGATGTGCAGCTGGCATTCCTT } \\
\text { R: AGTCATTGCTCTGCAGATGGGCTA }\end{array}$ & 100 & 60 & 686 \\
\hline Hyaluronidase I & $\begin{array}{l}\text { F: ACTGCAGCAATCACAAAGGCTGAC } \\
\text { R: TATTTGCTGGACTGGTGCCTCTCA }\end{array}$ & 100 & 60 & 294 \\
\hline Hyaluronidase II & $\begin{array}{l}\text { F: AACGTGTGGAGCACTACATTCGGA } \\
\text { R: GAACTGCTGTGCTGCGAACTCAAA }\end{array}$ & 100 & 60 & 215 \\
\hline Hyaluronidase III & $\begin{array}{l}\text { F: TTACAGTCAACCCTCCCAAGCACA } \\
\text { R: TTAGCACTTTACCGACCTTCGCCA }\end{array}$ & 100 & 60 & 280 \\
\hline Lysyl Oxidase & $\begin{array}{l}\text { F: ATGATCACAGGGTGCTGCTCAGAT } \\
\text { R: GTGTGCAGTACATGCAAATCGCCT }\end{array}$ & 100 & 60 & 260 \\
\hline GAPDH (control) & $\begin{array}{l}\text { F: TGGCAAATTCCATGGCACCGTCAA } \\
\text { R: TTGACAAAGTGGTCGTTGAGGGCA }\end{array}$ & 100 & 62 & 768 \\
\hline Fibromodulin & $\begin{array}{l}\text { F: CACTTTCCTCCACAGATGCC } \\
\text { R: GCTGCTTTCTCAATCCAGCC }\end{array}$ & 100 & 62 & 387 \\
\hline MMP-12 (macrophage elastase) & $\begin{array}{l}\text { F: CTGCTGATGACATACGTGGC } \\
\text { R: GTTTGGGATAACCAGGGTCC }\end{array}$ & 100 & 62 & 498 \\
\hline
\end{tabular}

$\mathrm{AT}=$ annealing temperature; $\mathrm{bp}=$ product base pairs; $\mathrm{F}=$ forward; $\mathrm{R}=$ reverse;

$\mathrm{GAPDH}=$ glyceraldehyde 3 -phosphate dehydrogenase; $\mathrm{MMP}=$ matrix metalloproteinase

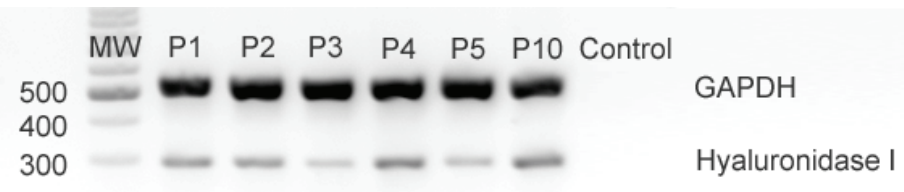

Figure 1. An example of PCR agarose gel, showing PCR products generated from RNA extracted from primary-culture human vocal fold fibroblasts of passages 1-5 (P1-P5) and passage 10 (P10) for the hyaluronidase I target primer as shown in Table $1(\mathrm{MW}=100$ base pair DNA molecular weight marker, Amresco, Solon, OH). 


\subsection{Measurement of Population Doubling Time}

In order to examine the rate of proliferation of the primary vocal fold fibroblasts, the cumulative doubling of the cells was measured by the population doubling time (PDT). PDT is the time interval required for dividing cells to double in number [14]. To calculate PDT, a fixed number $\left(1 \times 10^{4}\right.$ cells $)$ of vocal fold fibroblasts of a certain passage (passages 2 to 10 ) were seeded in each well of a 6-well plate. After 72 hours, the cells from each well were collected and counted with a hemocytometer, with the number of cells designated as $\mathrm{N}_{\mathrm{T}}$. Assuming that the number of cells increases exponentially, at the end of $n$ generations; each single cell would yield $2^{n}$ cells. Thus, after 72 hours, $1 \times 10^{4}$ seeded cells would produce $\mathrm{N}_{\mathrm{T}}=$ $\left(10^{4} \times 2^{n}\right)$ cells at harvest. The number of generations $(n)$ equals to $3.32\left(\log \mathrm{N}_{\mathrm{T}}-\log 10^{4}\right)$. By definition, PDT is the total time elapsed divided by the number of generations. PDT of the corresponding passage can be obtained by the following equation [14]:

$$
\mathrm{PDT}=72 / 3.32\left(\log \mathrm{N}_{\mathrm{T}}-\log 10^{4}\right)
$$

\subsection{Reverse Transcriptase-Polymerase Chain Reaction (RT-PCR)}

Total RNA was extracted with TRIzol reagent $(2 \mathrm{ml})$ (Invitrogen, Carlsbad, CA) using a modification of the method of Chomczynski and Sacchi [15] from fibroblasts grown to $80 \%$ confluence $\left(\sim 2 \times 10^{6}\right.$ cells) in two $175 \mathrm{~cm}^{2}$ flasks, for each of passages 1-5 and 10 .

All primers for PCR analysis were obtained through Invitrogen (Carlsbad, CA). Primers for specific targets and the standard control, glyceraldehyde 3-phosphate dehydrogenase (GAPDH), are listed in Table 1 along with annealing temperature (AT), product size in base pairs (bp), and the source of the primer sequences. Primer sequences for those targets designed in the present study were based on sequences published by the NIH GenBank database, using the SciTools software of Integrated DNA Technologies (Coralville, IA). Targets were chosen based on their contributions to and demonstrated roles in the maintenance of the vocal fold extracellular matrix $[1,16,17]$. Furthermore, analyses of collagenase (MMP-1), macrophage elastase (MMP-12) and the three isoforms of hyaluronidases (I, II, and III) were analyzed for conversion of fibroblasts from a matrix-synthesizing to a matrix-degrading phenotype. This transition serves as a hallmark indicator of the process of replicative senescence [5].

A master stock $(1 \mathrm{mM})$ of each primer was used to generate a working stock $(10 \mu \mathrm{M})$ for each PCR reaction. All reactions were carried out using the OneStep RTPCR kit (Qiagen, Valencia, CA) coupling the cDNA synthesis and PCR steps. For each reaction $(12.5 \mu \mathrm{l}$ total volume), the following components were added, with the final concentrations or amounts noted in brackets: target forward and reverse primers [400-600 nM], GAPDH forward and reverse primers [600nM-1500 nM], $1 \times$ RT-PCR buffer (including $\mathrm{MgCl}_{2}[12.5 \mathrm{mM}]$ ), nucleotides [400 $\mu \mathrm{M}$ of each], template RNA (100 ng), RNa$\sin ^{\circledR}$ RNAse inhibitor [7 U] (Promega, Houston, TX) and the OneStep RT-PCR Enzyme Mix [1:25] (Qiagen, Valencia, CA). Four pairs of primers for the GAPDH control were used to match four different target annealing temperatures (Table 1).

Reactions were incubated using a Mastercycler personal thermal cycler (Eppendorf, Westbury, NY) using a protocol with an initial denaturation $\left(94^{\circ} \mathrm{C}\right.$ for $\left.3 \mathrm{~min}\right)$ and 29-37 cycles of the following steps: denaturation $\left(94^{\circ} \mathrm{C}\right.$ for $\left.30 \mathrm{sec}\right)$, annealing $\left(50^{\circ} \mathrm{C}, 56^{\circ} \mathrm{C}, 60^{\circ} \mathrm{C}\right.$ or $62^{\circ} \mathrm{C}$ for $30 \mathrm{sec})$ and elongation $\left(72^{\circ} \mathrm{C}\right.$ for $\left.1 \mathrm{~min}\right)$. As a final step, PCR products were extended for $7 \mathrm{~min}$ at $72^{\circ} \mathrm{C}$. PCR products were electrophoresed in $0.5 \times \mathrm{TAE}$ buffer on $2 \%$ agarose gels and visualized for densitometric analysis using a FluorChem HD2 gel documentation system (Alpha Innotech, San Leandro, CA). An example of an agarose gel containing PCR products for the hyaluronidase I target primer is shown in Figure 1. To verify that the optical density of the PCR products was in the linear range, three reactions, each with RNA purified from a different passage, were loaded using two different volumes ( 3 and $5 \mu \mathrm{l}$ ). PCR products for each target and for GAPDH were compared using densitometric analysis with the gel documentation system. To indicate the relative mRNA expression for each target gene, the densitometric ratio of the target relative to GAPDH was plotted as a function of the passage number.

\subsection{Statistical Analysis}

For the population doubling time data, one-way analysis of variance (ANOVA) was conducted to determine if the proliferation rates of the vocal fold fibroblasts in different passages were significantly different from one another. The level of significance (alpha) was set at 0.01 . For the densitometric results of mRNA expressions obtained from RT-PCR, one-way ANOVA was also performed across all passages for each given target. If the ANOVA results reached statistical significance $(p<0.01)$, post-hoc analysis was done using the Tukey honestly significant difference (HSD) test for all possible pairwise comparisons of passages (e.g., P1-P2, P3-P4, $\mathrm{P} 5-\mathrm{P} 10$, etc.). Those pairwise comparisons that contribute to an overall trend of increase or decrease in the mRNA expressions of a particular target were deemed particularly important for the purpose of examining the effect of passaging or replicative senescence. Also, the results of the P5-P10 comparisons are shown separate to the other pairwise comparisons, in order to highlight the effect of replicative senescence in late passages. 


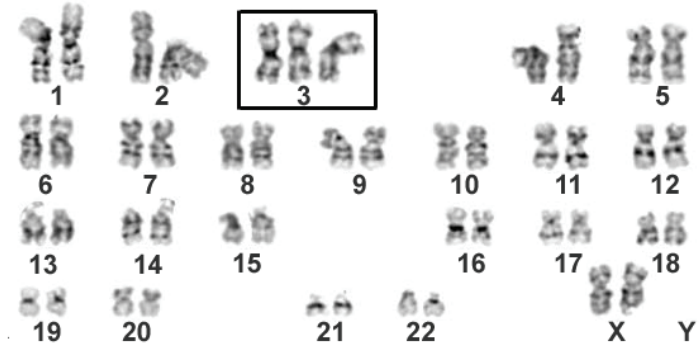

Figure 2. Passage $1(\mathrm{P} 1)$ karyotype: Systematic array (karyotype) of G-banded chromosomes from P1 visualized by Giemsa stain showing an allotment of 23 pairs of chromosomes including the sex chromosomes, with three copies of chromosome 3 observed in 3 of 20 cells examined (boxed area) (only arrays with chromosomal aberrations are shown).

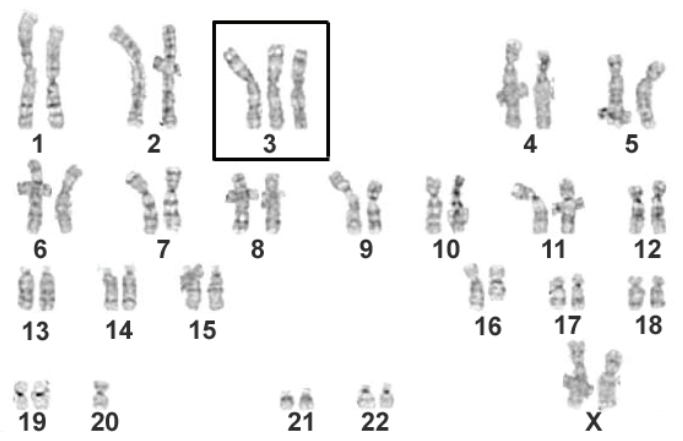

Figure 3. Passage 2 (P2) karyotype: An array showing three copies of chromosome 3 (boxed area). Karyotypically normal according to Mitelman [18].

\section{RESULTS}

\subsection{Characterization of Vocal Fold Fibroblast Karyotype}

Chromosomal analysis indicated the presence of an additional cell line (noted in 3 of 20 metaphase cells analyzed) in passage 1 (P1) with three copies of chromosome 3 (47, XX, +3[3]/46, XX [17]) (Figure 2, boxed area). The same anomaly was also found in both passage 2 (P2) and passage 3 (P3), revealing a degree of pseudo-mosaicism in 5\% of the cells karyotyped (Figures 3 and 4, boxed areas). The term "pseudo-mosaicism" can be used because the number of cells (one) displaying the +3 karyotype fell below the minimum number of cells (two) to be considered a separate clone [18]. The finding of trisomy 3 can then be considered as statistically insignificant, i.e., a "random gain". Hence, P2 and P3 are considered to be karyotypically normal based on this criterion. For passage 4 (P4), trisomy of chromosome 3 similar to that of $\mathrm{P} 1$ was observed in 3 of 20 cells, while the other cells displayed a normal female karyotype (Figure 5, boxed area).

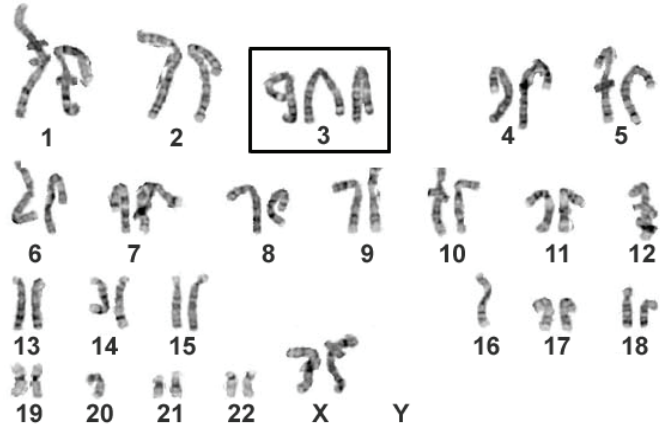

Figure 4. Passage 3 (P3) karyotype: As in P2, three copies of chromosome 3 were found (boxed area). Karyotypically normal according to Mitelman [18].

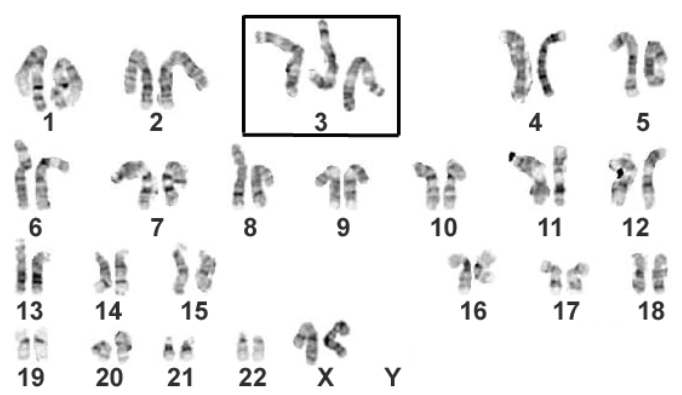

Figure 5. Passage 4 (P4) karyotype: Hyperploidy in $\mathrm{P} 4$ as indicated by three copies of chromosome 3 (boxed area).

For passage 5 (P5), three distinct cell lines were apparent. In 3 of 20 cells, three copies of chromosome 3 were observed (Figure 6A, boxed area), along with two cells showing trisomy of both chromosomes 3 and 8 (Figure 6B, boxed and circled areas, respectively). Hence, the karyotype for P5 was 47, XX, +3[3]/48, XX, $+3+8[2] / 46$, XX [15]. For passage 10 (P10), 4 of 20 cells exhibited the following chromosomal aberrations: translocation occurring as a two-break rearrangement; breakage and reunion at bands 13 and 13.1 of the short arms (p) of chromosomes 1 and 19, respectively (Figure 7A, boxed area). The regions distal to these bands have been swapped. In addition, one of the sex chromosomes has been deleted, yielding the following karyotype: $45, \mathrm{X}$, -X, t(1, 19)(p13, p13.1) [cp4]/46, XX [16]. Trisomy 8 (Figure 7B, circled area) was not listed in the karyotype, as it was considered a "random gain" [18]. Results for the cytogenetic analysis are summarized in Table 2.

\subsection{Population Doubling Time}

Figure 8 shows the mean cumulative population doubling time (PDT) of the vocal fold fibroblasts as a function of sub-culturing. The cumulative PDT was seen to increase across different passages, from approximately 30 hours in P2 to over 600 hours for P10. An especially sharp rise in PDT was associated with the transition 

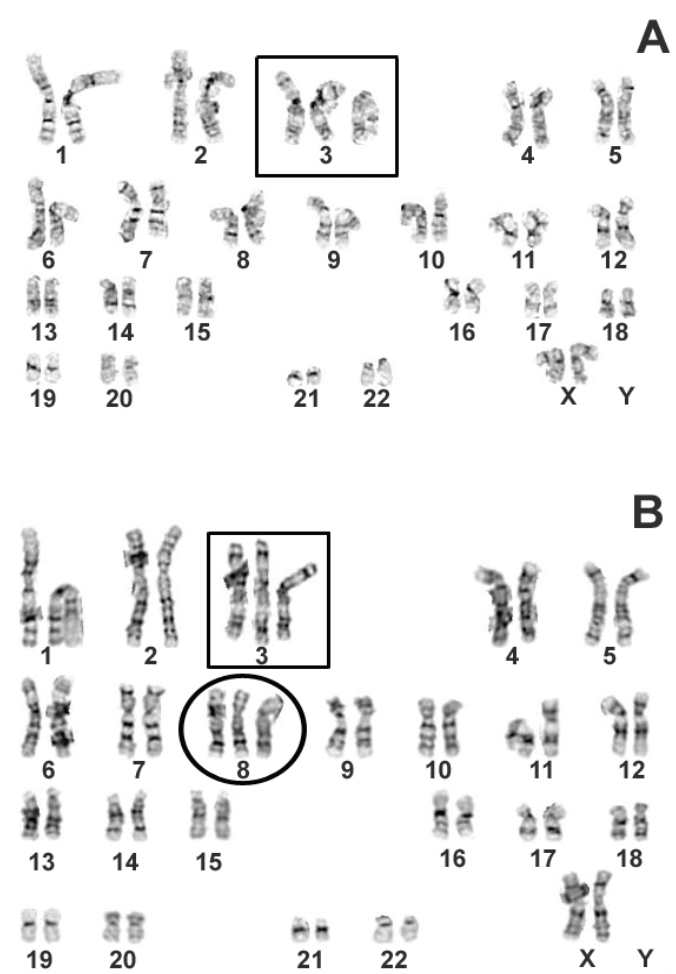

Figure 6. Passage 5 (P5) karyotype: (A) Triploidy of chromosome 3 as seen in P1-P4 (boxed area); (B) An additional clone was detected displaying +8 abnormality (circled area).

Table 2. Results of cytogenetic analysis.

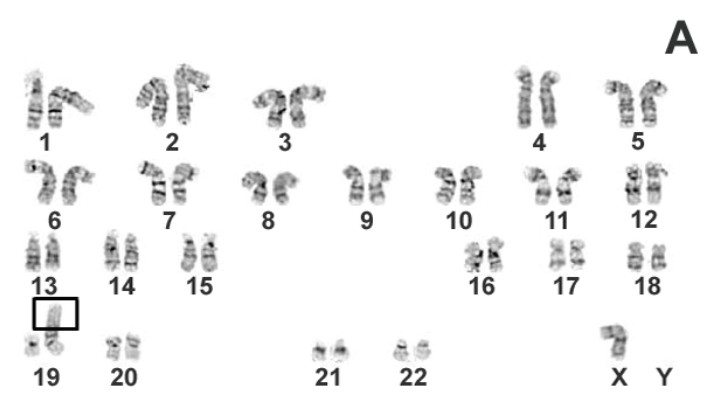

B

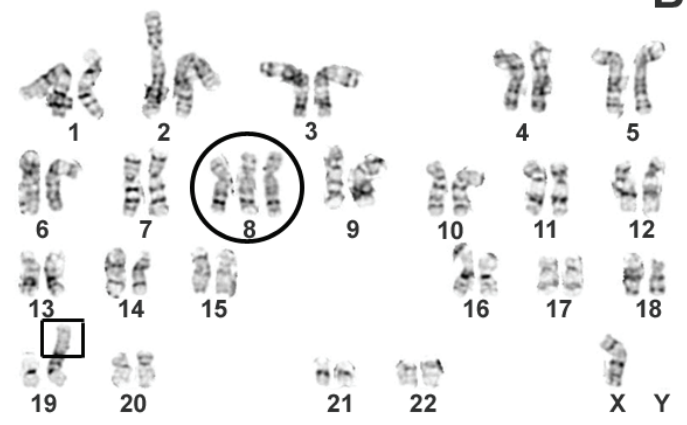

Figure 7. Passage 10 (P10) karyotype: (A) A translocation has occurred as a two break rearrangement. The region distal to band 13 on the short arm of chromosome 1 has attached to band 13.1 of chromosome 19 (translocation portion indicated in the boxed area). There was also the loss of one sex chromosome; (B) One cell out of four also displayed three copies of chromosome 8 (circled area) and was considered a "random gain".

\begin{tabular}{ccc}
\hline Passage number & Cells with normal diploid karyotype / Total no. of cells & Karyotype $^{\mathrm{a}}$ \\
\hline 1 & $17 / 20$ & $47, \mathrm{XX},+3[3] / 46, \mathrm{XX}[17]$ \\
2 & $19 / 20$ & $47, \mathrm{XX},+3[1] / 46, \mathrm{XX}[19]$ \\
3 & $19 / 20$ & $47, \mathrm{XX},+3[1] / 46, \mathrm{XX}[19]$ \\
4 & $17 / 20$ & $47, \mathrm{XX},+3[3] / 46, \mathrm{XX}[17]$ \\
5 & $15 / 20$ & $47, \mathrm{XX},+3[3] / 48, \mathrm{XX},+3+8[2] / 46, \mathrm{XX}[15]^{\mathrm{b}}$ \\
10 & $16 / 20$ & $45, \mathrm{X},-\mathrm{X}, \mathrm{t}(1 ; 19)(\mathrm{p} 13 ; \mathrm{p} 13.1)[\mathrm{cp} 4] / 46, \mathrm{XX}[16]^{\mathrm{c}}$ \\
\hline
\end{tabular}

${ }^{a}$ The normal diploid clone was listed at the end of the karyotype, along with square brackets [ ], indicating the absolute number of cells in each clone [18]. ' Abnormal clones were listed according to their size with the greatest absolute number first [18]. "The designation "cp" for composite karyotype was used because 1 out of 4 cells displayed an additional copy of chromosome $8(+8)$ as seen in Figure 7B. As a result, the four cells represented a composite of three aberrations. Trisomy 8 was not listed in the karyotype as it was considered a "random gain".

from P7 to P8, suggesting a significant slowing down of cellular proliferation. Results of single-factor ANOVA indicated that the differences in PDT across the passages were statistically significant $(F(8,18)=4.8450, p<0.005)$. These findings suggested that the vocal fold fibroblasts have undergone the process of replicative senescence, since it has been shown that replicative senescence is partially signified by an increase in PDT [19].

\subsection{RT-PCR}

The changes in mRNA expressions of the select target genes across different passages are shown as densitometric ratios of the targets versus the standard control, glyceraldehyde 3-phosphate dehydrogenase (GAPDH) in Figure 9. Table 3 summarizes the results of statistical analysis on the dependence of these mRNA expressions 


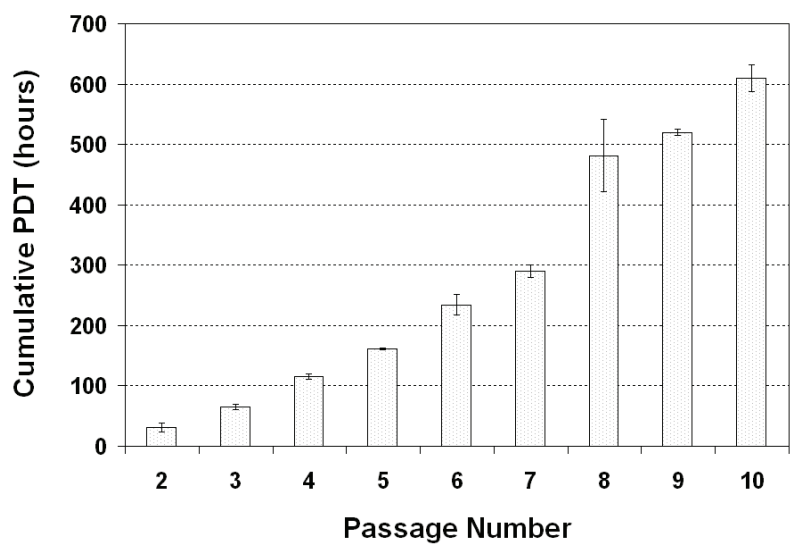

Figure 8. Cumulative population doubling time (PDT) of primary vocal fold fibroblasts as a function of passaging (means \pm standard error of the mean; $n=3$ ).

on passaging. Pairwise comparisons of passages were analyzed to detect any possible trends over the passages. P5-P10 differences are listed separately for targets that are consistent with induction of senescence. First, for matrix-degrading enzymes, the transcript levels of MMP-1 (collagenase) showed significant increases from the early passages to passage 10, e.g., a three-fold increase from P5 to P10 (Figure 9A) $(p<0.01)$. For MMP-12 (macrophage elastase), there was a gradual and significant increase in its mRNA expressions from $\mathrm{P} 2$ to $\mathrm{P} 5(p<0.01)$, and then a dramatic, significant decrease to P10 $(p<0.01)$ (Figure 9B). Both MMP-1 and MMP-12 are implicated in the remodeling process of the vocal fold ECM, and the upregulation of MMP-12 has been closely associated with aging [20]. Hyaluronidase I showed a considerable upregulation from the early passages to $\mathrm{P} 10$, particularly from P5 to P10 $(p<0.01)$ (Figure 9C). The levels of hyaluronidase II showed a significant increase from the early passages to $\mathrm{P} 5$, and then a significant decrease to P10 (both at the $p<0.01$ level) (Figure 9D). For the crosslinking enzyme lysyl oxidase, significant increases in mRNA levels were observed with passaging from P3 to $\mathrm{P} 5$, and from P4 to P10 $(p<0.01)$. The increases were approximately two-fold (Figure $9 \mathrm{E}$ ).

For procollagen I, the precursor to the al peptide of collagen I, there was a pronounced decrease in mRNA levels across the passages $(p<0.01)$ (Figure 9F). For collagen III, the transcript levels of collagen III $\alpha 1$ decreased significantly across the passages $(p<0.01)$ (Figure 9G). For fibromodulin (a proteoglycan important for the structural organization of collagen), there was an overall reduction in its mRNA levels across the passages, particularly from $\mathrm{P} 1$ to $\mathrm{P} 3$ and then from $\mathrm{P} 5$ to $\mathrm{P} 10$, where the decrease was 17 -fold $(p<0.01)$ (Figure 9H). For decorin, also important for collagen organization,

Table 3. Results of ANOVA and post-hoc pairwise comparisons of mRNA expressions of target genes across different passages.

\begin{tabular}{|c|c|c|c|c|}
\hline \multicolumn{3}{|c|}{ A N O VA } & \multicolumn{2}{|c|}{ Post-hoc Tukey HSD Test } \\
\hline Target & $F(5,12)$ & $p$ & $\begin{array}{l}\text { Significant differences for } \\
\text { the following comparisons }\end{array}$ & $\begin{array}{l}\text { Significant differences } \\
\text { for P5-P10? }\end{array}$ \\
\hline MMP-1 (Collagenase) & 218.1 & $2.4 \times 10^{-11}$ & P5-P10 & Yes \\
\hline MMP-12 (macrophage elastase) & 10.3 & $5.14 \times 10^{-4}$ & P2-P5, P4-P10, P5-P10 & Yes \\
\hline Hyaluronidase Type I & 9.5 & $7.4 \times 10^{-4}$ & P5-P10 & Yes \\
\hline Hyaluronidase Type II & 196.5 & $4.5 \times 10^{-11}$ & $\begin{array}{c}\mathrm{P} 1-\mathrm{P} 5, \mathrm{P} 2-\mathrm{P} 5, \\
\mathrm{P} 3-\mathrm{P} 5, \mathrm{P} 3-\mathrm{P} 10, \mathrm{P} 4-\mathrm{P} 5, \mathrm{P} 5-\mathrm{P} 10\end{array}$ & Yes \\
\hline Lysyl Oxidase & 101.6 & $2.15 \times 10^{-9}$ & $\begin{array}{c}\text { P1-P2, P1-P3, P1-P4, } \\
\text { P2-P3, P2-P4, P2-P5, P2-P10, } \\
\text { P3-P10, P4-P5, P4-P10 }\end{array}$ & No \\
\hline Procollagen I & 126.1 & $6.1 \times 10^{-10}$ & $\begin{array}{l}\text { P1-P3, P1-P4, P1-P5, P1-P10, } \\
\text { P2-P3, P2-P4, P2-P5, P2-P10, } \\
\text { P3-P5, P3-P10, P4-P5, P4-P10 }\end{array}$ & No \\
\hline Collagen III $(\alpha 1)$ & 848.9 & $7.3 \times 10^{-15}$ & $\begin{array}{c}\text { P2-P3, P2-P4, P2-P5, P2-P10, } \\
\text { P3-P4, P3-P5, P3-P10, } \\
\text { P4-P5, P4-P10, P5-P10 }\end{array}$ & Yes \\
\hline Fibromodulin & 126.2 & $6.1 \times 10^{-10}$ & $\begin{array}{c}\text { P1-P2, P1-P3, P1-P4, P1-P5, } \\
\text { P1-P10, P2-P3, P2-P10, } \\
\text { P3-P5, P3-P10, P5-P10 }\end{array}$ & Yes \\
\hline Decorin & 30.2 & $2.12 \times 10^{-6}$ & $\begin{array}{l}\mathrm{P} 1-\mathrm{P} 5, \mathrm{P} 1-\mathrm{P} 10, \mathrm{P} 2-\mathrm{P} 4, \mathrm{P} 2-\mathrm{P} 5 \\
\mathrm{P} 2-\mathrm{P} 10, \mathrm{P} 3-\mathrm{P} 10, \mathrm{P} 4-\mathrm{P} 10\end{array}$ & No \\
\hline HA-synthase 2 & 15.16 & $7.92 \times 10^{-5}$ & P1-P3, P1-P5, P1-P10 & No \\
\hline Collagen I $(\alpha 2)$ & 1.7 & 0.21 & \multirow{4}{*}{ not applicable } & \multirow{4}{*}{ not applicable } \\
\hline HA Receptor (CD44) & 2.1 & 0.137 & & \\
\hline Fibronectin & 2 & 0.149 & & \\
\hline Hyaluronidase Type III & 1.5 & 0.264 & & \\
\hline
\end{tabular}



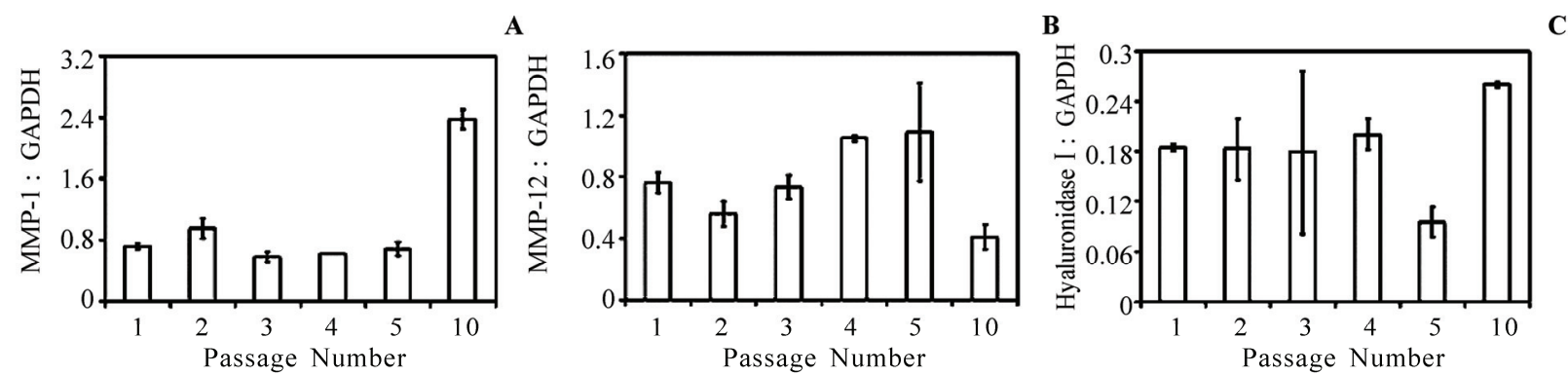

D
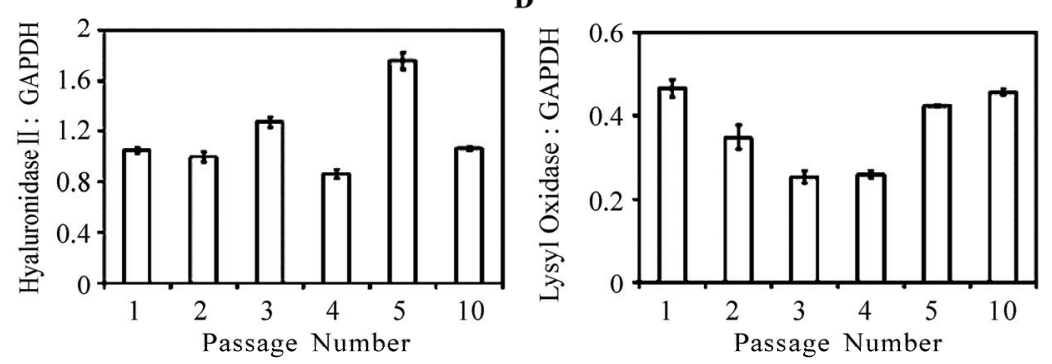

$\mathbf{E}$

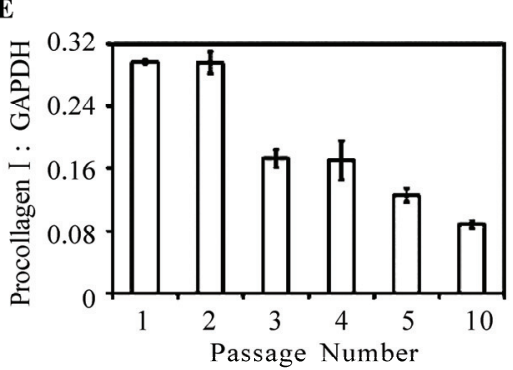

G

H
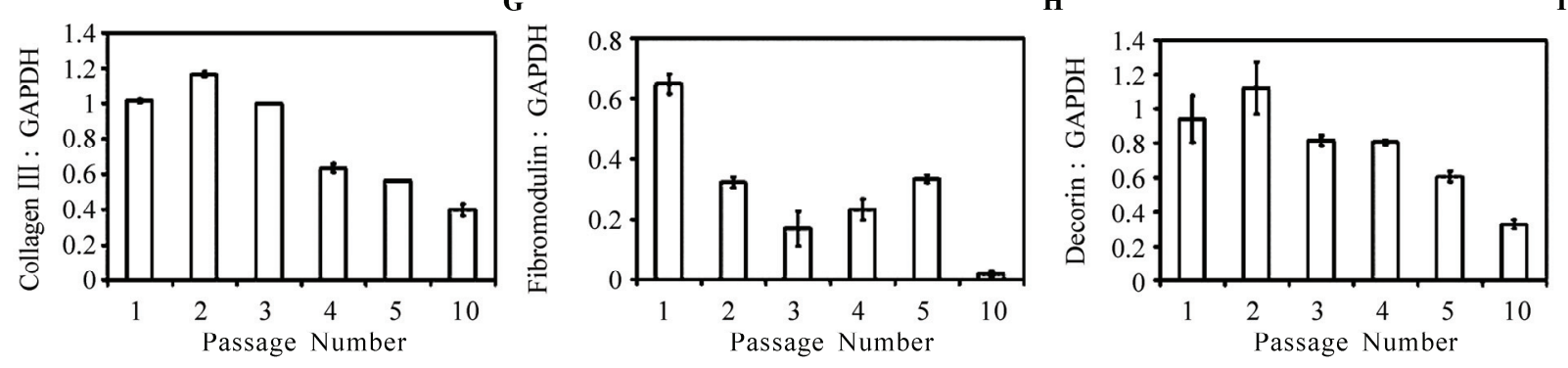

$\mathbf{J}$

K

$\mathbf{L}$
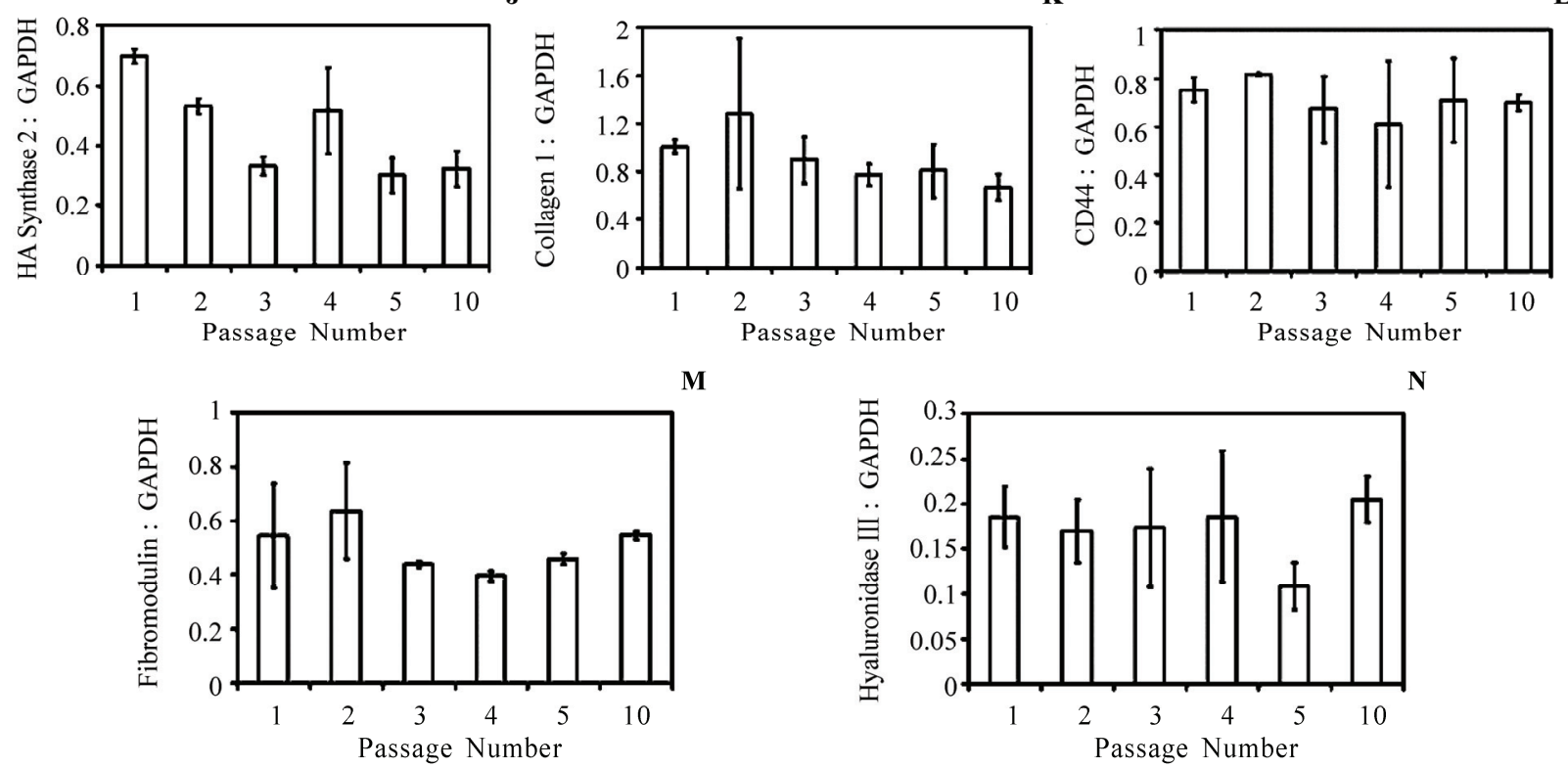

Figure 9. Densitometric ratios for select extracellular matrix target genes (means \pm standard deviations; $n=3$ ), showing the integrated density volumes (IDV) or cumulative grey scale values of PCR agarose gel bands for each target relative to those of the standard control (GAPDH): (A) MMP-1 ${ }^{*}$ (collagenase), (B) MMP-12 ${ }^{*}$ (macrophage elastase), (C) hyaluronidase ${ }^{*}$, (D) hyaluronidase $\mathrm{II}^{*}$, (E) lysyl oxidase ${ }^{*},(\mathrm{~F})$ procollagen $\mathrm{I}^{*},(\mathrm{G})$ collagen $\mathrm{III}^{*},(\mathrm{H})$ fibromodulin ${ }^{*},(\mathrm{I})$ decorin ${ }^{*},(\mathrm{~J})$ HA-synthase $2^{*}$, $(\mathrm{K})$ collagen I, (L) CD44, (M) fibronectin, and (N) hyaluronidase III $\left({ }^{*} p<0.01\right)$. 
there was a significant decrease in its mRNA levels across the passages. For instance, the overall reduction from P1 to P10 was approximately three-fold $(p<0.01)$ (Figure 9I). For the matrix-synthesizing enzyme HAsynthase 2 , there was a significant overall trend of decrease from $\mathrm{P} 1$ to $\mathrm{P} 10(p<0.01)$, despite an increase from P3 to P4. In particular, significant differences were found from the early passages to P10 (Figure 9J).

For the following target genes, no statistically significant changes in mRNA expressions were detected as a function of passaging $(p>0.01)$ : collagen I $\alpha 2$ (Figure 9K), the HA receptor CD44 (Figure 9L), fibronectin (Figure 9M) and hyaluronidase III (Figure 9N).

\section{DISCUSSIONS}

One objective of this study was to establish the onset and extent of gross chromosomal aberrations in human vocal fold fibroblasts associated with in vitro aging, or replicative senescence. Chromosomal aberrations were documented by karyotyping as a function of sub-culturing, or passaging. Next, alterations in the mRNA expressions for some key matrix proteins at the transcript level were observed for the vocal fold fibroblasts across passages, in order to characterize the consequence of the chromosomal aberrations due to aging in vitro.

From the cytogenetic analysis, the +3 karyotype observed in the first four passages (P1-P4) should not be considered as a significant chromosomal aberration, particularly for P2 and P3, where the fibroblasts were classified as karyotypically normal according to ISCN standards [18]. Beyond passage 4, however, it was apparent that an additional cell line has appeared with the karyotype $(+3,+8)$ which conceivably could be the result of a nondisjunction with mother cell with a +3 karyotype. Aberrations observed in passage 5 in this study were comparable to those of passage 4 in Thibeault et al. [7]. Yet the severity of the aberrations in this study was relatively modest, e.g., trisomy 8 in 3 cells of 20 in P4 in this study versus the numerous anomalies in P4 of Thibeault et al. [7], including the loss of sex chromosome in 6 of 21 cells, translocation in 3 of 21 cells; and rearrangement involving chromosomes $2,5,10,14,15$. This disparity in the number and severity of chromosomal abnormalities was likely due to the difference in age of the donors of the studies (58 years old in this study versus 78 years old in Thibeault et al. [7]). The susceptibility of vocal fold fibroblasts to these aberrations apparently increased with age and should be targeted in future studies.

Based on the RT-PCR analysis for those target genes demonstrating statistically significant differences across different passages, our data on the changes in mRNA expressions of the targets can be divided roughly into two categories: 1) target genes involving matrix-synthesizing enzymes and matrix-degrading enzymes, in- cluding MMP-1, MMP-12, hyaluronidases, and HAsynthase 2; and 2) targets contributing to the regulation of the ECM organization, including procollagen I, collagen III, decorin, fibromodulin, and lysyl oxidase.

For target genes involving matrix-synthesizing and matrix-degrading enzymes, it has been considered that the shift of fibroblasts from a matrix-synthesizing to a matrix-degrading phenotype is one of the hallmark indicators for replicative senescence [5]. This notion was supported by numerous studies that showed upregulation of matrix metalloproteinases (MMPs) in senescent fibroblasts $[21,22,23]$. Such a shift towards a matrix-degrading phenotype was demonstrated in the present study by the modulations observed in the following targets.

The upregulation of both MMP-1 (collagenase) and MMP-12 (macrophage elastase) with passaging of human vocal fold fibroblasts is consistent with in vitro aging seen in other kinds of fibroblasts, such as dermal fibroblasts $[24,25,26]$. Hyaluronidases are responsible for the cleavage of hyaluronic acid (HA). Type I and type II hyaluronidases are the most common isoforms expressed in human somatic tissues [27]. HA, a highly polarized long-chain glycosaminoglycans molecule, is abundantly found in the vocal fold lamina propria [28]. It is critical to the regulation of tissue hydration and is important for the maintenance of an optimal viscoelasticity of the lamina propria for vocal fold vibration $[2,4,28]$. From the PCR analysis, the upregulation of hyaluronidase II from $\mathrm{P} 1$ to P5 and the upregulation of hyaluronidase I from P5 to P10 were consistent with a proposed model for their concerted action in the degradation of HA [28]. Specifically, hyaluronidase II cleaves HA first into $20 \mathrm{kDa}$ fragments, followed by hyaluronidase I digesting them into smaller fragments [29]. Accumulation of the $20 \mathrm{kDa}$ fragments leads to an increase in transcripts of hyaluronidase I by mass action, as seen in P10. The actions of these enzymes in concert were consistent with a shift towards a matrix-degrading phenotype.

Mammalian HA synthesis is accomplished in part by HA-synthase 2 [16]. The levels of HA-synthase 2 showed a steady decrease from P1 to P3, and remained at low levels for P5 and P10, indicating that the synthesis of HA has been reduced in these fibroblasts. This finding further supported our argument that across the passages, vocal fold fibroblasts have shifted from a matrix-synthesizing to a matrix-degrading phenotype, consistent with replicative senescence.

The changes in mRNA expressions of the remaining targets strongly implicated that the in vitro aging of these fibroblasts would lead to a disorganized and structurally compromised lamina propria ECM. First, for collagen III $\alpha 1$, which is a major structural fibrous protein of the vocal fold lamina propria and macula flava [30,31], there was a steady and significant decrease in the transcript level with passaging. Type III collagen fibers were found 
to be thicker than type I fibers, with their interactions likely contributing to the viscoelasticity of the lamina propria and the tensile strength of the macula flava necessary for bearing the mechanical stresses of vocal fold vibration [32]. For procollagen I, a significant decrease in its mRNA levels was also seen with passaging. This downregulation did not correspond to a significant decrease in collagen I mRNA levels, because different peptides were coded for the two targets ( $\alpha 1$ for procollagen I and $\alpha 2$ for collagen I). Our findings of collagen III, collagen I and procollagen I expressions suggested a lower turnover rate for collagen, leading to an ECM increasingly cross-linked and difficult to degrade, as observed in aged human vocal folds [33].

Decorin contributes to regulate the organization and overall size of collagen fibrils via its glycosaminoglycans moiety [34], presumably reducing collagen fiber size and density [35]. Lower levels of decorin have been associated with disorganized collagenous supramolecular assemblies in scar tissue [36]. The observed decrease in the transcript levels of decorin along with the decrease in collagen III suggested that the capability of fibroblasts for facilitating structural ECM organization has been impaired due to aging in vitro.

Fibromodulin is a small proteoglycan that facilitates the construction of other proteins such as collagens I and II into fibrillar structures [17]. It has been shown that fibromodulin-knockout mice have disorganized collagen fibrils in their Achilles tendons, with reduced overall cross-sectional area when compared to normal control [37]. Our results showed a dramatic, significant 17 -fold decrease in the level of fibromodulin from P5 to P10. Combined with the decorin data, lower fibromodulin levels supported the notion that the capability of the fibroblasts for ECM protein organization is compromised with passaging.

The cross-linking enzyme lysyl oxidase catalyzes the removal of amino groups from certain hydroxylysine and lysine residues in collagen, cross-linking one collagen molecule to another [38]. Lysyl oxidase is apparently the only known enzyme responsible for crosslinking elastin monomers [39]. Such cross-linking would likely increase the elastic modulus for both collagen and elastin fibers. Increases in tissue stiffness of the vocal fold lamina propria and the macula flava have been seen with aging [17,37], which could be related to the increased cross-linking of collagen and elastin fibers. Our data showed a clear upregulation in lysyl oxidase from P3 to P10, consistent with this modulation in vocal fold tissue stiffness with aging.

These results, along with the dramatic decrease in macrophage elastase (MMP-12) from P5 to P10, suggested that the gene expressions of senescent vocal fold fibroblasts in vitro are consistent with a proposed model for in vivo aging of the vocal fold. This model suggests that as vocal folds age, elastin fibers accumulate with a prolonged half-life due to lower elastase levels and undergo extensive cross-linking via lysyl oxidase, contributing to increased tensile strength and tissue stiffness. The increase in lysyl oxidase levels with passaging in our study contradicted the results for aged rats in Ding and Gray [39], but may nonetheless reflect inherent differences between the species, and between in vitro and in vivo models.

Overall, based on our data on cytogenetic analysis, PDT and mRNA expressions of target genes, we have established the sub-culturing limit beyond which replicative senescence was observed in primary-culture human vocal fold fibroblasts. This limit of 5 passages was critical for establishing representative in vitro models for tissue engineering approaches involving the use of primaryculture fibroblasts. For example, primary vocal fold fibroblasts seeded in decellularized ECM scaffolds have been shown to be promising for vocal fold regeneration [8]. The therapeutic potential of injection of autologous fibroblasts as well as the incorporation of growth factors or biomaterial implants with fibroblasts for treating vocal fold scarring has also been targeted [9,10,40]. In those studies, autologous fibroblasts were harvested by biopsy and sub-cultured for up to the sixth passage, for up to 30 days. The current findings suggested that some of the fibroblasts in those studies may have become senescent, compromising their findings and conclusions.

Nonetheless, it should be noted that the results of this study should be considered preliminary, based on the harvest of vocal fold fibroblasts from only a single individual. Also, the vocal fold fibroblasts were only cultured statically, unlike in physiological situations when they are subjected to a variety of mechanical stresses, particularly vibratory stresses. Titze et al. showed that axial and vibratory strains applied to human vocal fold fibroblasts cultured on a polymeric substrate resulted in significant changes in mRNA expressions of a number of matrix proteins [9]. Further studies involving bioreactors capable of simulating the micromechanical environment in vivo are required to address this important issue. In addition, the measurement of gene expressions at the transcript level does not always directly reflect expressions of the corresponding proteins. Changes in mRNA expression of a certain protein would depend on the half-life of that protein, and on its regulation pathways. Future studies should therefore involve the measurement of protein levels with methods such as enzyme-linked immunosorbent assays.

\section{CONCLUSIONS}

In summary, the patterns of chromosomal abnormalities and mRNA expressions of matrix proteins across different passages of primary-culture vocal fold fibroblasts indicated that the fibroblasts underwent replicative se- 
nescence, with the onset of senescence not occurring before the fifth passage. These preliminary data suggested that an acceptable limit of sub-culturing may be established to facilitate the development of representative in vitro models of the vocal fold ECM, allowing for the evaluation of a variety of tissue engineering approaches for vocal fold reconstruction.

\section{ACKNOWLEDGEMENTS}

This study was supported by the National Institutes of Health, NIDCD Grant No. R01 DC006101. The authors would like to thank Dr. J.T. Hsieh for the use of his gel documentation system, and Glendon Plumton for his assistance in the RT-PCR work.

\section{REFERENCES}

[1] Gray, S.D. (2000) Cellular physiology of the vocal folds. Otolaryngologic Clinics of North America, 33, 679-698.

[2] Gray, S. D., Titze, I. R., Chan, R. and Hammond, T.H. (1999) Vocal fold proteoglycans and their influence on biomechanics. Laryngoscope, 109, 845-854.

[3] Hirano, S. (2005) Current treatment of vocal fold scarring. Current Opinion in Otolaryngology \& Head and Neck Surgery, 13, 143-147.

[4] Chan, R.W., Gray, S.D. and Titze, I.R. (2001) The importance of hyaluronic acid in vocal fold biomechanics. Otolaryngology Head and Neck Surgery, 124, 607-614.

[5] Cristofalo, V.J., Lorenzini, A., Allen, R.G., Torres, C. and Tresini, M. (2004) Replicative senescence: A critical review. Mechanisms of Ageing \& Development, 125, 827-848.

[6] Campisi, J. (1998) The role of cellular senescence in skin aging. Journal of Investigative Dermatology Symposium Proceedings, 3, 1-5.

[7] Thibeault, S.L., Li, W., Gray, S.D. and Chen, Z. (2002) Instability of extracellular matrix gene expression in primary cell culture of fibroblasts from human vocal fold lamina propria and tracheal scar. Annals of Otology, Rhinology, Laryngology, 111, 8-14.

[8] Xu, C.C., Chan, R.W. and Tirunagari, N. (2007) A biodegradable, acellular xenogeneic scaffold for regeneration of the vocal fold lamina propria. Tissue Engineering, 13, 551-566.

[9] Titze, I.R., Hitchcock, R.W., Broadhead, K. et al. (2004) Design and validation of a bioreactor for engineering vocal fold tissues under combined tensile and vibrational stresses. Journal of Biomechanics, 37, 1521-1529.

[10] Hirano, S., Bless, D.M., Nagai, H., Rousseau, B., Welham, N.V., Montequin, D.W. and Ford, C.N. (2004) Growth factor therapy for vocal fold scarring in a canine model. Annals of Otology, Rhinology, Laryngology, 113, 777-785.

[11] Alberts, B., Johnson, A., Lewis, J., Raff, M., Roberts, K. and Walter, P. (2002) Molecular Biology of the Cell, 4th Edition. Garland Science, New York, 1313-1362.

[12] Sato, K., Miyajima, Y., Izumaru, S. and Nakashima, T. (2008) Cultured stellate cells in human vocal fold mucosa. Journal of Laryngology \& Otology, 122, 13391342.

[13] Richardson, A. (1997) Chromosome analysis. In Barch,
M., Knutsen, T. and Spurbeck, J. (eds.), The AGT Cytogenetics Laboratory Manual. Lippincott-Raven, Philadelphia, 495-496.

[14] McAteer, J. and Davis, J. (2002) Basic cell technique and the maintenance of cell lines. In Davis, J. (ed.), Basic Cell Culture: A Practical Approach. Oxford University Press, New York, 135-189.

[15] Chomczynski, P. and Sacchi, N. (1987) Single-step method of RNA isolation by acid guanidinium thiocyanate-phenol-chloroform extraction. Analytical Biochemistry, 162, 156-159.

[16] Girish, K.S. and Kemparaju, K. (2007) The magic glue hyaluronan and its eraser hyaluronidase: A biological overview. Life Sciences, 80, 1921-1943.

[17] Hedbom, E. and Heinegard, D. (1993) Binding of fibromodulin and decorin to separate sites on fibrillar collagens. Journal of Biological Chemistry, 268, 27307-27312.

[18] Mitelman, F. (1995) ISCN 1995: An International System for Human Cytogenetic Nomenclature: Recommendations of the International Standing Committee on Human Cytogenetic Nomenclature. S. Karger Publishers, Basel, Switzerland.

[19] Campisi, J. (1997) The biology of replicative senescence. European Journal of Cancer, 33, 703-709.

[20] Tsai, K.K., Chuang, E.Y., Little, J.B. and Yuan, Z.M. (2005) Cellular mechanisms for low-dose ionizing radiation-induced perturbation of the breast tissue microenvironment. Cancer Research, 65, 6734-6744.

[21] Frechet, M., Warrick, E., Vioux, C. et al. (2008) Overexpression of matrix metalloproteinase 1 in dermal fibroblasts from DNA repair-deficient/cancer-prone xeroderma pigmentosum group C patients. Oncogene, 27, 5223-5232.

[22] Liu, D. and Hornsby, P.J. (2007) Senescent human fibroblasts increase the early growth of xenograft tumors via matrix metalloproteinase secretion. Cancer Research, 67, 3117-3126.

[23] Rijken, F., Kiekens, R.C., van den Worm, E., Lee, P.L., van Weelden, H. and Bruijnzeel, P.L. (2006) Pathophysiology of photoaging of human skin: Focus on neutrophils. Photochemical \& Photobiological Sciences, 5, 184-189.

[24] Millis, A.J., Hoyle, M., McCue, H.M. and Martini, H. (1992) Differential expression of metalloproteinase and tissue inhibitor of metalloproteinase genes in aged human fibroblasts. Experimental Cell Research, 201, 373-379.

[25] Millis, A.J., McCue, H.M., Kumar, S. and Baglioni, C. (1992) Metalloproteinase and TIMP-1 gene expression during replicative senescence. Experimental Gerontology, 27, 425-428.

[26] West, M.D., Pereira-Smith, O.M. and Smith, J.R. (1989) Replicative senescence of human skin fibroblasts correlates with a loss of regulation and overexpression of collagenase activity. Experimental Cell Research, 184, 138-147.

[27] Csoka, A.B., Scherer, S.W. and Stern, R. (1999) Expression analysis of six paralogous human hyaluronidase genes clustered on chromosomes $3 \mathrm{p} 21$ and $7 \mathrm{q} 31$. Genomics, 60, 356-361.

[28] Butler, J.E., Hammond, T.H. and Gray, S.D. (2001) Gender-related differences of hyaluronic acid distribution in the human vocal fold. Laryngoscope, 111, 907-911.

[29] Csoka, A.B., Frost, G.I. and Stern, R. (2001) The six hyaluronidase-like genes in the human and mouse ge- 
nomes. Matrix Biology, 20, 499-508.

[30] Madruga de Melo, E.C., Lemos, M., Aragao Ximenes Filho, J., Sennes, L.U., Nascimento Saldiva, P.H. and Tsuji, D.H. (2003) Distribution of collagen in the lamina propria of the human vocal fold. Laryngoscope, 113, 2187-2191.

[31] Paulsen, F., Kimpel, M., Lockemann, U. and Tillmann, B. (2000) Effects of ageing on the insertion zones of the human vocal fold. Journal of Anatomy, 196, 41-54.

[32] Tateya, T., Tateya, I. and Bless, D.M. (2006) Collagen subtypes in human vocal folds. Annals of Otology, Rhinology, Laryngology, 115, 469-476.

[33] Sato, K., Hirano, M. and Nakashima, T. (2002) Agerelated changes of collagenous fibers in the human vocal fold mucosa. Annals of Otology, Rhinology, Laryngology, 111, 15-20.

[34] Ruhland, C., Schonherr, E., Robenek, H. et al. (2007) The glycosaminoglycan chain of decorin plays an important role in collagen fibril formation at the early stages of fibrillogenesis. FEBS Journal, 274, 4246-4255.

[35] Hahn, M.S., Kobler, J.B., Zeitels, S.M. and Langer, R. (2005) Midmembranous vocal fold lamina propria proteoglycans across selected species. Annals of Otology,
Rhinology, Laryngology, 114, 451-462.

[36] Thibeault, S.L., Bless, D.M. and Gray, S.D. (2003) Interstitial protein alterations in rabbit vocal fold with scar. Journal of Voice, 17, 377-383.

[37] Svensson, L., Aszodi, A., Reinholt, F.P., Fassler, R., Heinegard, D. and Oldberg, A. (1999) Fibromodulin-null mice have abnormal collagen fibrils, tissue organization, and altered lumican deposition in tendon. Journal of Biological Chemistry, 274, 9636-9647.

[38] Lucero, H.A. and Kagan, H.M. (2006) Lysyl oxidase: An oxidative enzyme and effector of cell function. Cellular and Molecular Life Sciences, 63, 2304-2316.

[39] Ding, H. and Gray, S.D. (2001) Senescent expression of genes coding tropoelastin, elastase, lysyl oxidase, and tissue inhibitors of metalloproteinases in rat vocal folds: Comparison with skin and lungs. Journal of Speech, Language, Hearing Research, 44, 317-326.

[40] Chhetri, D.K., Head, C., Revazova, E., Hart, S., Bhuta, S. and Berke, G.S. (2004) Lamina propria replacement therapy with cultured autologous fibroblasts for vocal fold scars. Otolaryngology Head and Neck Surgery, 131, 864-870. 